\title{
La delimitación de las relaciones léxicas en el marco del diccionario
}

\author{
CARMEN VARO VARO \\ Universidad de Cádiz
}

\section{EL ESTATUS DE LAS RELACIONES LÉXICAS EN LA PRAXIS LEXICOGRÁFICA}

\subsection{La divergencia entre los enfoques semántico y lexicográfico}

La separación entre la práctica lexicográfica y los fundamentos teóricos en los que, se supone, debe basarse esta, se manifiesta en el tratamiento de las relaciones léxicas en los diccionarios. En esta línea, la mayoría de las compilaciones de sinónimos y antónimos incluye un repertorio más o menos extenso de voces afines, donde caben, además de sinónimos, hiperónimos y antónimos, otras relaciones de proximidad semántica o referencial, sin mucho rigor científico en cuanto a su ordenación o conexión con la entrada léxica ni ejemplificación. Junto a estos trabajos, también ciertos diccionarios generales monolingües, contienen en sus artículos lexicográficos una parte paradigmática que incorpora sinónimos, antónimos y otras voces relacionadas ${ }^{1}$.

Si confrontamos los enfoques semántico y lexicográfico, comprobamos que, en tanto que sinonimia, hiperonimia-hiponimia y antonimia son caracterizadas desde los estudios sobre el significado léxico como relaciones de similitud, inclusión y contraste sémico, respectivamente, desde la perspectiva del diccionario, estas son interpretadas como relación entre expresiones que pueden alternar en ciertos contextos, en el caso de la sinonimia, como subtipo de sinonimia contextual, en el caso de la hiperonimiahiponimia, y como relación entre expresiones frecuentemente polarizadas, si se trata de la antonimia. Aunque no dudamos de su interés práctico y estamos de acuerdo con que los fines son distintos a los de la investigación teórica de estos fenómenos lingüísticos, observamos en la mayoría de las obras lexicográficas un tratamiento asistemático, disperso e insuficiente de las relaciones léxicas ${ }^{2}$, pese a su vital importancia para el aprendizaje de la lengua materna o extranjera.

\footnotetext{
${ }^{1}$ Sobre la microestructura de los diccionarios generales, en la que se incluyen estas relaciones, se trata en Garriga Escribano (2003: 103-126). Para un estudio de las principales informaciones lexicográficas ofrecidas en Moliner (1966-1967), cf. Casas Gómez, Penadés Martínez y Díaz Hormigo (1998).

${ }^{2}$ Este hecho resulta particularmente llamativo, si tenemos en cuenta, de acuerdo con Haensch (1997: 35), que «una de las aportaciones más relevantes de la lingüística moderna a la lexicografía han sido 
En este marco, por su indudable relevancia, reseñaremos aquí uno de los principales problemas observados en el tratamiento de la sinonimia, la hiperonimia-hiponimia y la antonimia en estos trabajos. En concreto, abordaremos la indistinción de subtipos de estas relaciones, acompañando esta revisión crítica de algunas propuestas dirigidas a mejorar y enriquecer la integración de estas relaciones en los diccionarios.

\subsection{Principales problemas en el tratamiento de las relaciones léxicas en los diccionarios}

Como hemos señalado antes, pese a las diversas propuestas de caracterización y sistematización de las relaciones léxicas elaboradas desde distintas teorías lingüísticas ${ }^{3}$, tales desarrollos han recibido escasa atención tanto en los diccionarios como en los repertorios específicos de sinónimos y antónimos generales de español, que generalmente se limitan a consignar listas de palabras, sin ofrecer apenas explicaciones sobre las relaciones y diferencias entre estas, atendiendo especialmente a su uso.

En lo que atañe a la sinonimia, de la consulta de muchos de estos diccionarios se desprende una concepción vaga. A veces, inexplicablemente, en los diccionarios generales con información paradigmática, no se consigna ningún sinónimo, como ocurre, por ejemplo, con las relaciones de verbos tan frecuentes en español como alegrar, castigar, decir y poner ${ }^{4}$. Respecto a la hiperonimia-hiponimia, totalmente ausente como relación diferenciada de la sinonimia en los diccionarios y basada en la inclusión semántica, esta se concibe como un tipo más de relación sinonímica, como se observa en el Diccionario de sinónimos, ideas afines y contrarios (1996) de Taurus, en el que el hiperónimo de abdicar, renunciar, forma parte de la lista de sinónimos proporcionados. Menor atención recibe también la antonimia ${ }^{5}$, relación que ocupa un lugar claramente secundario frente a la sinonimia en las obras lexicográficas, por lo que es común la falta de inclusión del antónimo o la limitación a simplemente uno de ellos en el caso de muchas entradas, en clara desproporción frente a las extensas listas de sinónimos que suelen incorporar ${ }^{6}$.

Por otra parte, desconcierta, en cuanto a la inclusión de las relaciones léxicas en los diccionarios, el orden en que aparecen consignadas estas, basado generalmente en el criterio alfabético en lugar de en la frecuencia de uso. De este modo, encontramos dic-

y son los resultados de la semántica moderna, especialmente para el análisis del significado de las palabras y su descripción lexicográfica».

${ }^{3}$ En efecto, la caracterización y el análisis tipológico de estas relaciones se remontan a los estudios clásicos y ocupan un lugar central en la Semántica léxica, en la que, desde distintos enfoques, numerosos autores se han ocupado de ellas. Para una revisión historiográfica del tratamiento de estas relaciones en los estudios léxicos, cf. Casas Gómez (1999: 12-38) y Varo Varo (2007: 21-55).

${ }^{4}$ Hemos consultado, en este caso, el Diccionario Escolar de la Lengua Española (1993) y el Diccionario Básico Didáctico del Español (1997).

${ }^{5}$ La menor atención dedicada a esta relación se pone de relieve en la mayoría de los prólogos de estos repertorios, donde encontramos alguna que otra consideración en torno a la sinonimia, pero prácticamente nada sobre la antonimia. En líneas generales, observamos una concepción muy poco precisa, en la que parece darse por supuesto su comprensión por parte del usuario, frente a la sinonimia, de la que siempre se comentan algunos aspectos.

${ }^{6}$ Como muestra de ello, el diccionario antes citado no incluye el antónimo de abajo. 
cionarios donde los sinónimos más comunes de una palabra ocupan una posición más distante que los menos usados por la mayoría de los hablantes.

Atendiendo a la caracterización semántica de estas relaciones presente en las obras lexicográficas, queremos resaltar, en primer lugar, la concepción tradicional de sinonimia y antonimia como manifestaciones contrarias ${ }^{7}$, tomada de importantes dominios de la investigación lexicológica, donde las nociones de similitud y contrariedad, no quedan nada claras. Se trata de relaciones semánticas que aunque, a primera vista, parecen ser diametralmente opuestas la una a la otra, en un análisis lingüístico detallado muestran compartir una base semántica común y ciertos rasgos diferenciales, si bien en las relaciones sinonímicas es la similitud semántica la que domina, mientras que en las relaciones antonímicas se impone la polaridad (cf. Geckeler, 1989: 260). Además, la antonimia, frente a la sinonimia y la hiperonimia-hiponimia, muestra una fuerte dependencia del significante, pues todos los antónimos tienen sinónimos que los hablantes no identifican de forma tan inmediata como tales. Así pues, la intuición de la antonimia no puede ser explicada únicamente a través del punto de vista semántico, por lo que la contemplamos como relación entre signos completos vinculados tanto en su significado como en su significante.

Una de las causas principales de la ausencia de sistematicidad en el tratamiento de las relaciones léxicas en los diccionarios es el problema de la indistinción de signos agrupados bajo una misma expresión. La falta de delimitación entre significados correspondientes, en realidad, a signos distintos o invariantes y meras invariantes de contenido de una misma unidad o acepciones de habla ${ }^{8}$ no es solo un denominador común de la práctica lexicográfica, sino que se origina en importantes dominios de la teoría semántica. Se trata de un enfoque que es consecuencia de tomar el significante y no el significado como punto de partida en el análisis del contenido semántico de las palabras $^{9}$ y que afecta a la configuración de las propias entradas del diccionario.

Justamente, el establecimiento de relaciones sinonímicas y antonímicas con distintos signos lingüísticos constituye uno de los criterios fundamentales para delimitar signos (cf. Gutiérrez Ordóñez, 1981: 159) que, como tales, debieran aparecer consignados en entradas independientes, junto con sus correspondientes sinónimos y antónimos. De este modo, la expresión pronto ${ }^{10}$ designa el adjetivo que significa 'veloz, acelerado, ligero', que se relaciona sinonímicamente también con rápido y antonímicamente con tardio; el sustantivo que significa 'decisión repentina motivada por una pasión u ocurrencia inesperada', cuyo sinónimo es arrebato, y, finalmente, el adverbio que significa 'con anticipación al momento oportuno, con tiempo de sobra', que se contrapone a tarde; con lo cual tendríamos tres signos distintos, prontol (adjetivo),

${ }^{7}$ En el ámbito de la lexicografía, Smith introduce el término antonym (antónimo), como sustituto de la noción general de opposite (opuesto), en su diccionario Synonyms and Antonyms (1867), como contrapunto al de synonym (sinónimo) (cf. Gove, 1968: 26a).

${ }^{8}$ Para una revisión de este problema, cf. Casas Gómez (2008: 283-306 y 2006: 829-844).

${ }^{9}$ Una propuesta de delimitación de invariantes de contenido léxico, con la que se pretende afrontar el problema de la polisemia puede verse en Muñoz Núñez (1999).

${ }^{10}$ Tomamos las acepciones de los ejemplos aquí consignados de la última versión del DRAE (22. ${ }^{\mathrm{a}}$ ed.). 
pronto 2 (sustantivo) y pronto 3 (adverbio), que no solo pertenecen a distintas categorías gramaticales sino que además contraen distintas relaciones léxicas, que merecen ser marcadas lexicográficamente. Asimismo, el distinto comportamiento sintagmático de los significantes en cuestión se erige como un criterio fundamental para establecer fronteras entre signos. Este, por ejemplo, nos permite diferenciar, al menos, tres signos materializados en la expresión abandonar: abandonarl 'dejar, desamparar a alguien o algo', abandonar 2 'dejar una ocupación, un intento, un derecho' y abandonar3 'dejar un lugar, apartarse de él', a los que subyacen diferentes esquemas oracionales: alguien abandona a alguien, alguien abandona algo y alguien abandona un lugar (cf. Penadés Martínez, 1994: 204-205) y que contraen distintas relaciones sinonímicas y antonímicas.

Dejando a un margen estos problemas, principalmente la inexistencia de un acuerdo teórico uniforme tanto en las caracterizaciones como en las clasificaciones de las relaciones léxicas ${ }^{11}$ justifica la indistinción de subtipos en el ámbito lexicográfico y, como consecuencia, el tratamiento unitario de estos fenómenos, pese al interés práctico de estas informaciones desde el punto de vista del usuario del diccionario.

\section{LOS SUBTIPOS DE SINÓNIMOS EN EL DICCIONARIO}

\subsection{La delimitación entre variación y relación léxicas}

En el marco de la sinonimia, teniendo en cuenta la convivencia en el diccionario de las perspectivas variacionista y sistemática, conviene delimitar, como paso previo esencial, las relaciones propiamente léxicas, sustentadas en la coexistencia de rasgos de similitud y contraste en las unidades implicadas, de los hechos de variación libre y de variación diasistemática. Efectivamente, en el caso de la sinonimia en términos absolu$\operatorname{tos}^{12}$, basada en la total identidad de los significados paradigmáticos y sintagmáticos que subyacen a dos o más expresiones, que coincide con el concepto de variación libre, no se podría hablar propiamente de relaciones léxicas, al no existir rasgos diferenciales. Tampoco, como en el caso de la sinonimia absoluta, como posibilidad sistemática, en la variación de carácter diasistemático, sería posible hablar de relaciones léxicas, dado que las diferencias entre unas variantes y otras no dependen de su significado, sino de otros aspectos.

\footnotetext{
${ }^{11}$ Para una revisión terminológica del concepto de relación léxica y una propuesta de clasificación de este, cf. Casas Gómez (2005: 5-31).

${ }_{12}$ Las diferentes posturas sobre esta cuestión oscilan desde la creencia en su legitimidad hasta los que llevan su negación a las últimas consecuencias, pasando por aquellos que aceptan esta posibilidad aunque con ciertas reservas. En realidad, el problema no consiste tanto en el dilema de la existencia o no de la sinonimia, sino en qué entendemos por sinonimia, dependiendo esta elección de un conjunto de factores entre los que destacamos la concepción que tengamos acerca del contenido semántico. En cierto modo la sinonimia absoluta constituye un hecho innecesario que la lengua no tolera, pues se opone a nuestra particular concepción del lenguaje.
} 
Sin duda, este último tipo de variación merece una atención especial por su interés para el usuario del diccionario ${ }^{13}$. Sin considerar la variación diacrónica ${ }^{14}$, que separa estados de lengua, y la geográfica, que marca diferencias entre la lengua estándar y la lengua dialectal, por poder exceder ambos tipos el sentido tradicional del diccionario de sinónimos y antónimos, nos interesa destacar la importancia de los registros y estilos, teniendo en cuenta que un mismo individuo utiliza la lengua de distinto modo en diferentes situaciones comunicativas.

En un estado de lengua, dentro de una misma comunidad geográfica es posible encontrar diferencias de naturaleza social que interesa marcar lexicográficamente. Especial interés cobran, en esta línea, las aportaciones de los estudios de Sociolingüística, que se ocupan de esta variación y reconocen la existencia de sociolectos o conjunto de hechos lingüísticos que aparecen en un estrato social determinado. Así, la delimitación entre elementos léxicos ubicados en sociolectos altos, medios y bajos constituye una de las apuestas más ambiciosas por sus aplicaciones en el ámbito de la enseñanza de lenguas (cf. Moreno Fernández, 2000: 51-52). Por otra parte, se ha de considerar que el modelo la lengua culta, constituido por los rasgos lingüísticos que caracterizan el habla de las personas de mejor formación de una comunidad, no se trata más que de una idealización recogida en las gramáticas, como advierte Moreno Fernández (2000: 52), por lo que resulta más enriquecedor para los hablantes conocer muestras del amplio espectro de este tipo de variación.

En lo que concierne a la presencia de la variación léxica de carácter estilístico en el diccionario, de extraordinaria importancia para la enseñanza de la lengua, además de contribuir en gran medida a valorar la información relativa a las situaciones y los contextos, es decir, el papel de los estilos, nos introduce en uno de los aspectos centrales de los lenguajes de especialidad o lenguajes con fines específicos, pues es evidente que el conocimiento de las manifestaciones léxicas de los tipos de lenguajes fundamentales con los que se enfrenta el individuo cotidianamente será de inestimable ayuda para su producción e interpretación concretas.

Por consiguiente, variantes diasistemáticas, como coche-carro, dinero-pasta, marpiélago, vinculados a distintos dialectos, sociolectos y estilos, respectivamente, pueden señalarse, precisamente por no ser intercambiables en el texto, a menos que se persiga crear efectos estilísticos. Este tipo de información nos parece imprescindible para el enriquecimiento léxico desde una vertiente cualitativa, ya que supondría el establecimiento de fronteras entre sinónimos diatópicos, diastráticos y diafásicos, de indiscutible relevancia no solo para fomentar el uso adecuado, sino también para la interpretación de textos ubicados en diversos diasistemas lingüísticos.

${ }^{13}$ Por otra parte, «estas diferencias no se han puesto siempre de relieve con la claridad y consecuencia deseables» (Haensch et al., 1982: 380).

${ }^{14}$ Cf., en este sentido, Jiménez Ríos (2001: 15), que sobre esta cuestión señala: «La variación lingüística de la que se ocupan disciplinas como la dialectología, la sociolingüística o, incluso, la estilística y la pragmática, aparece recogida en el diccionario, pero sin más método que el puramente intuitivo con el que han contado los lexicógrafos hasta fechas muy recientes para realizar su trabajo». 


\subsection{La delimitación de cuasinónimos, parasinónimos y relaciones de hiperonimia- hiponimia}

Ahora bien, si asumimos la inestabilidad de la equivalencia absoluta, negada por numerosos autores (cf. Casas Gómez, 2004: 41-69), y la complejidad para recoger de forma completa y organizada la variación de tipo diasistemática, las informaciones proporcionadas por los diccionarios se concentran en ofrecer un amplio espectro de relaciones de similitud no bien delimitadas, que presentan diversos problemas en los que también debemos detenernos. A ello se suma la ausencia de límite «entre lo que se podría aun llamar sinónimo y lo que es palabra afín» (Haensch, 1997: 68).

En primer lugar, los denominados cuasisinónimos, si bien comparten gran número de rasgos que posibilitan su intercambio, no son mutuamente sustituibles en todos los contextos, ya sea por diferencias combinatorias o bien por divergencias basadas en la norma de la lengua en cuestión, como se aprecia en la relación entre los sustantivos daño y perjuicio, que comparten la dimensión sémica 'efecto sobre algo o alguien', según se muestra en los textos que aquí recogemos ${ }^{15}$.

a) A un médico cubano, el Dr. Moras Escobar, le preguntaron en una ocasión sobre el d a ñ o (p e r j u i c i o) que causa el fumar [...]. (Diario de las Américas, 21/04/1997: ¿Es acabar con las compañias tabacaleras lo que se busca?, EEUU.) b) En una carta enviada a Vistazo, Cisneros dice que su caso se volvió un escándalo porque alguien interesado en hacer d a ñ o (*p e r j u i c i o) a partidos políticos, insinuó [...]. (Vistazo, 19/06/1997: Droga, política y fútbol: el caso de Diego Cisneros, Ecuador)

c) Por otra parte, la policía de nuestra ciudad, por violar la ley 10.081, de caza furtiva, inició actuaciones en p e r j u i c $i$ o (*d a ñ o) de Javier Eduardo Hermosilla [...]. (La Nueva Provincia, 21/07/1997: Imita a Mingo, 1997, Argentina)

En segundo lugar, los parasinónimos, o pares de unidades léxicas que difieren en una única marca que se organiza de modo equipolente entre los miembros de la oposición, aunque comparten algunos rasgos, nunca son intercambiables ${ }^{16}$, lo que los acerca al tipo de comportamiento observado en la antonimia. La cuestión es que en las relaciones parasinonímicas se focalizan los rasgos sémicos comunes, mientras que en la antonimia hay un predominio de los rasgos diferenciales. Lo comprobamos con pares como eficiente-eficaz, donde las unidades léxicas implicadas difieren en un único componente semántico, que es suficientemente relevante como para que nunca puedan alternar en el uso.

d) Este año pondremos todo nuestro empeño para que la Fracción Parlamentaria de Convergencia mejore su calidad de participación en la actividad legislativa, por lo que haremos un trabajo más intenso y más ef i c i e $n$ te e [...]. (El Universal, 21/01/1997: Convergencia mejorará trabajo parlamentario, Venezuela)

${ }^{15}$ Estos ejemplos, así como los restantes, los hemos tomado del Corpus de Referencia del Español Actual (CREA), elaborado por la Real Academia Española

${ }^{16}$ Este funcionamiento se explica por apoyarse la relación de parasinonimia (tomo / volumen, valiente / temario, etc.), al igual que la antonimia, en una relación semántica de equipolencia (cf. Varo Varo, 2006: 826). 
e) A pesar de que el litio fue un fármaco muy e $f$ i c a $z$ que apareció cuando más se necesitaba [...]. (El Mundo - Salud (Suplemento), 10/07/1997: Psiquiatría, España)

Por último, el uso de los hiperónimos, como partir respecto a zarpar o despegar, confundidos, como ya hemos señalado, con sinónimos, constituye un tipo de sustitución contextual que es factible solo cuando no interesa perseverar en el rasgo específico, por haber sido ya antes puesto de relieve o por ser innecesaria la especificación para nuestros fines comunicativos. Este hecho ha sido observado en el pasado por autores como Lyons (1971: 474-484), que interpretará el fenómeno sinonímico, como dependiente del contexto, puesto que los casos de sinonimia pueden producirse como consecuencia de una relación de hiponimia, motivada bien por la referencia situacional del hiperónimo, bien por su modificación sintagmática ${ }^{17}$. De cualquier forma, nos parece necesario singularizar estas relaciones de inclusión semántica en el marco del diccionario, con objeto de diferenciarlas de las relaciones, antes mencionadas, de cuasinonimia, cuya alternancia depende de otros factores y, sobre todo, de parasinonimia, en las que no cabe la posibilidad de neutralización en el uso.

\section{LOS SUBTIPOS DE ANTÓNIMOS EN EL DICCIONARIO}

\subsection{El concepto de antonimia en la praxis lexicográfica}

Como ya hemos señalado, la antonimia ha recibido escasa atención en el ámbito lexicográfico, terreno en el que aún no se han llevado a la práctica los logros alcanzados en la Semántica actual, en la que se pretende diferenciar los distintos fenómenos ${ }^{18}$ que se engloban en ella. Como es sabido, desde una concepción amplia, bajo la etiqueta de antonimia se incluyen "pares de lexemas que se relacionan de manera diversa (alto / bajo, comprar / vender, macho / hembra, entrar / salir, derecha / izquierda, delante / detrás, etcétera)», cuyo único punto en común es la dependencia de la dicotomización (cf. Lyons, 1980: 254).

Como pauta general, en los diccionarios los antónimos reciben un tratamiento unitario, sin distinciones. Así, comprobamos que especialmente se consigna el antónimo o los antónimos del primero de los contenidos significativos. Por ejemplo, en el caso del

${ }^{17}$ Desde presupuestos muy distintos, Coseriu (1981: 224-225 n. 25) conectaba la neutralización con la sinonimia, al definir los sinónimos como elementos léxicos en oposición neutralizable. Entre las múltiples matizaciones a esta afirmación, se ha destacado que otras unidades léxicas no sinónimas, entre ellas antónimos graduables (junto a hiperónimos), pueden encontrarse en oposición neutralizable. Cf., en esta línea, Casas Gómez (1999: 102-106). Esta concepción de los sinónimos como términos en oposición neutralizable también fue antes sustentada, entre otros, por Rodríguez Adrados (1967: 210), autor que manifiesta que «la utilización del concepto de neutralización puede ser muy útil para resolver el problema de los sinónimos».

${ }^{18}$ Tal vez la tipología más difundida es la que distingue la antonimia graduable o relación entre términos regularmente graduables (gordo / delgado), la complementariedad o relación en la que la negación de uno de los elementos implica la afirmación del otro (macho / hembra), la inversión o relación entre elementos inversos (vender / comprar) y otras oposiciones direccionales (entrar / salir) (cf. Lyons, 1971: 474-484 y 1980: 263-270). Las distintas clasificaciones de esta relación léxica y los criterios para su sistematización son examinados en Varo Varo (2007: 21-110). 
adjetivo seco $^{19}$, el diccionario de Zainqui (1991) consigna una lista de antónimos más o menos aproximados, ordenados alfabéticamente, sin pormenorizar ni la relación que tienen con el término al que se oponen, ni la relación sinonímica que mantienen entre sí: bañado, calado, empapado, humedecido, húmedo, mojado, negado, rociado.

Esta falta de delimitación entre antónimos perfectos y antónimos más o menos aproximados hace necesaria la aplicación de criterios de frecuencia para determinar cuáles son las unidades léxicas que los hablantes identifican mayoritariamente como $\operatorname{tales}^{20} \mathrm{e}$, incluso, de pautas de carácter sociolingüístico, que posibiliten el deslinde de unidades léxicas marcadas diatópica, diastrática y diafásicamente, de aquellas generalizadas en el uso de la comunidad lingüística.

Frente a este proceder, en los diccionarios generales hallamos a veces una concepción más estrecha de esta, basada únicamente en la negación, patente en las llamadas definiciones antonímicas y más cercana a la lógica que a la lingüística, pues parece obviar la necesidad de la existencia de rasgos comunes para el establecimiento de una oposición de esta naturaleza, hecho que es puesto de relieve por María Moliner (196667, vol. I: 198). La autora del Diccionario de uso del español en la entrada antónimo, a modo de excurso gramatical, señala acertadamente que la recurrencia a perífrasis del tipo falto (falta) de «en muchos casos no es exacta, pues el antónimo que se trata de definir expresa una cualidad positiva y no meramente la falta de otra».

No obstante, la posibilidad de situar en puntos lo suficientemente distantes de una escala gradual los elementos en oposición ha sido y sigue siendo utilizada como el principal criterio lingüístico, exportado al ámbito lexicográfico, para caracterizar la noción de antonimia en sentido estricto y separarla de otros tipos de relación de contrariedad considerados menos relevantes o, incluso, excluidos por su dudosa naturaleza semántica (cf. Varo Varo, 2007: 66-73).

\subsection{Hacia una interpretación extensa de la antonimia en el diccionario}

Desde nuestro punto de vista, la relación de antonimia no debe limitarse a una concepción basada en la negación ni tampoco en la gradabilidad de los miembros. Frente a ello, creemos necesario incorporar en las obras lexicográficas una amplia tipología en la que se incluyan las diversas modalidades de esta relación identificadas por los hablantes ${ }^{21}$ :

1) La antonimia léxica escindida, en los casos de:

- Antonimia graduable, que puede relacionarse con

${ }^{19}$ A veces no es consignado ningún antónimo, quizás por el propio problema de determinar con exactitud cuáles son las distintas invariantes de contenido relacionadas con una expresión. Es lo que ocurre con seco en Blecua Perdices, dir. (1999).

${ }^{20}$ En muchas ocasiones dos elementos léxicos se convierten en antónimos en determinados contextos, con lo que más de una antonimia paradigmática, hablaríamos de una antonimia sintagmática. De hecho, la antítesis «no es estilísticamente otra cosa que la concurrencia en un texto de palabras antónimas» (Salvador, 1981:78).

${ }^{21}$ Basamos esta tipología en una propuesta en la que se combinan los criterios de base psicolingüística con el comportamiento lingüístico de cada par (cf. Varo Varo, 2007: 25-126 y 207-213). 
la emisión de juicios de valoración cuantitativa (escisión de valoración objetiva): grande / pequeño, alto / bajo, largo / corto, ancho / estrecho, frío / caliente, pesado / ligero, etc., o

$\checkmark \quad$ la emisión de juicios de valoración cualitativa (escisión de valoración subjetiva): bueno / malo, inteligente / tonto, valiente / cobarde, etc.

- Antonimia no graduable, vinculada a la clasificación de los objetos dentro de una categoría frente a otra (escisión categorial): hombre / mujer, día / noche, concreto / abstracto, etc.

2) La antonimia léxica deíctica, donde se incluirían aquellos pares referidos a:

- la ubicación por parte del individuo de los objetos en el espacio, fundamentalmente en las dimensiones horizontal y vertical (deixis espacial): cerca / lejos, arriba / abajo, delante / detrás, encima / debajo, etc.,

- la ubicación por parte del individuo de los objetos en el tiempo (deixis temporal): pasado / futuro, antes / después, pronto / tarde, etc.,

- la observación de sucesos como procesos que parten de un punto para culminar en otro (deixis espacio-temporal): empezar / terminar, nacer / morir, etc.,

- la observación del movimiento de los objetos e individuos en relación con el hablante o con un punto de referencia (deixis de movimiento): entrar / salir, subir / bajar, llegar / partir, etc.,

- las acciones del individuo que modifican el estado de los objetos o los devuelven a su estado inicial (deixis de manipulación de objetos): abrir / cerrar, apagar / encender, poner / quitar, etc.,

- la observación de sucesos como procesos que mantienen relaciones de consecuencia (deixis de consecuencia): buscar / encontrar, preguntar / responder, etc., $\mathrm{y}$

- la observación de sucesos como procesos que se producen simultáneamente (deixis de simultaneidad): comprar / vender, dar / recibir, hablar / escuchar, etc.

A partir de la delimitación de estos subtipos será posible establecer semejanzas y divergencias entre relaciones que se hallan encerradas incluso en expresiones homónimas, como es el caso de vivol 'Que tiene vida' / muertol 'Que está sin vida', que establecen una relación no graduable, frente a vivo2 'Intenso, fuerte' / muerto2 'Apagado, desvaído, poco activo o marchito', lo que explica su diferente comportamiento sintáctico:

f) No se sabe si ese niño está viv o o $m$ u e $r$ to. Y si efectivamente vive, las erráticas pesquisas para tratar de ubicarlo en Chile o en el extranjero probablemente mantendrán la duda por mucho tiempo. (Revista Hoy, 08/12/1996: Tráfico de menores, Chile)

g) Lo que es que yo tengo un poco la sensación, no sé si este debate nos está quedando un poco $m$ u e $r$ to (...). (Debate, TVE 1, 05/03/87: ¿Cambia de rumbo la Iglesia española?, Texto oral, España)

h) Para el técnico argentino, el Madrid sigue muy v $i$ v o en la Liga (...). (La Vanguardia, 16/10/1995: Carlos Novo, España) 


\section{CONCLUSIONES: ASPECTOS PARA LA INTEGRACIÓN DE LAS RELACIONES LÉXICAS EN EL DICCIONARIO}

Con objeto de llevar a cabo la tarea de integración de los diferentes subtipos de relaciones léxicas de manera coherente y sistemática en los diccionarios, nos parece necesario, como paso previo, establecer unos criterios de inclusión de tales relaciones fundamentados en estudios de coocurrencia en corpus de textos, así como en la frecuencia de uso y la disponibilidad léxica, para la incorporación posterior de estas en el diccionario. Además, debe partirse de la delimitación de significados correspondientes a signos distintos, que deben consignarse en diferentes entradas lexicográficas, para poder, gracias a ello, deslindar las relaciones sinonímicas, hiperonímicas y antonímicas vinculadas con cada uno. Una vez cumplidos estos prerrequisitos, es indispensable la introducción de una subclasificación de estas relaciones, especialmente en aquellos diccionarios destinados al aprendizaje del español.

La naturaleza de cada una de estas relaciones debe, de esta forma, ser singularizada, para que sea perfectamente interpretada por el usuario del diccionario. Así, desde nuestro punto de vista, la antonimia constituye una relación única, frente a la sinonimia y la hiperonimia-hiponimia, al estar organizada en torno a dos significantes determinados, pese a existir en cada polo de la relación sendas series sinonímicas que se reparten la esfera conceptual a la que remiten estos.

En la identificación de los correspondientes subtipos, se debe ir más allá de los tradicionalmente más estudiados. En efecto, la incorporación de otros subtipos de antónimos está plenamente justificada no solo por su naturaleza semántica, sino también por tratarse de relaciones que los hablantes de la lengua identifican con elevada frecuencia como tales. Por ejemplo, los verbos comprar y vender pertenecen a una misma esfera semántica, relativa a las transacciones comerciales, lo que nos permite delimitar una base común para los elementos léxicos mencionados. Además de ello, estos muestran simetría sintáctica, pues participan en construcciones que muestran similares relaciones de dependencia: alguien compra algo a alguien, alguien vende algo a alguien. Es decir, se trata de unidades léxicas con un valor relativo, cuya funcionalidad es completada por determinadas valencias sintácticas. Por otra parte, se trata de relaciones frecuentes en la lengua y que los hablantes identifican como un tipo de polaridad.

Debe, asimismo, contemplarse la posibilidad de adscribir ciertos pares a dos tipos de relación, que muestran un comportamiento sintagmático específico. Es el caso de aquellas unidades léxicas que encarnan los significados de abierto y cerrado, susceptibles de ser consideradas como ejemplo de antonimia graduable, si se interpreta como relación valorable en una escala, o de antonimia no graduable, si se conciben como las dos únicas opciones en una clasificación categorial.

La adopción de un enfoque distintivo nos parece, desde luego, fundamental si interesa destacar aquellas relaciones marcadas por la imposibilidad de mutuo intercambio o en las que la sustitución lleva aparejados determinados cambios no solo desde el punto de vista del significado sino también en el sentido del texto, así como aquellas en las que cada miembro de la serie sinonímica o del par antonímico manifiesta diferente 
conducta sintáctica. Esto ocurre cuando las unidades implicadas presentan diferencias en cuanto al dominio semántico que representan, como sucede con los binomios antonímicos inteligente-tonto y listo-torpe, representantes de esferas semánticas que no deben confundirse; existen diferencias de grado o de connotación, caso de la serie sinonímica delgado, flaco, escuálido, famélico; e incluso las unidades afectadas se insertan en diferente esquema sintáctico, en cuyo caso es preciso conocer la combinatoria exacta de cada una, como sucede en el par antonímico entrar- salir ${ }^{22}$.

En suma, las relaciones sinonímicas, hiperonímicas y antonímicas reclaman un tratamiento lexicográfico que participe de los avances alcanzados por la Semántica teórica. Resaltamos, frente a ello, el proceder de los lexicógrafos que pasan por alto la concepción del significado como compendio de rasgos sémicos deducibles por su relación. Por lo general el diccionario, en lugar de determinar, mediante la comparación con otras unidades, las marcas diferenciales de cada unidad léxica, parece actuar de forma contraria, haciendo desaparecer esos valores y, por tanto, equiparando unidades lingüísticas en realidad distintas. En el caso que nos ocupa, la tradicional falta de delimitación entre variantes léxicas y auténticas relaciones se similitud y contraste semántico, junto a la común indicación de conexiones de posible naturaleza referencial, confiando en la necesaria competencia lingüística o conocimiento del mundo para su correcta interpretación, hacen necesaria la adopción de un enfoque más sistemático de las relaciones léxicas, así como una delimitación de las fronteras semánticas entre cada una de sus modalidades en el marco del diccionario por su indiscutible interés para los usuarios de la lengua.

\section{REFERENCIAS BIBLIOGRÁFICAS}

Blecua Perdices, José Manuel, dir. (1999): Diccionario general de sinónimos y antónimos. VOX, Barcelona, Spes Editorial.

CASAS GóMEZ, Miguel (1999): Las relaciones léxicas, Tübingen, Max Niemeyer.

(2004): «Problemas lingüísticos implicados en la equivalencia semántica», en Actas del V Congreso de Lingüística General (León, 5-8 de marzo de 2002), Madrid, Arco/Libros, I, pp. 41-69.

(2005): «Relaciones "significativas", relaciones semánticas y relaciones léxicas», Lingüistica Española Actual, 27/1, pp. 5-31.

(2008): "El concepto de significante en el funcionalismo semántico», Romanische Forschungen, 120/33, pp. 283-306.

${ }^{22}$ La desigual combinatoria de ambas unidades se relaciona estrechamente con la diferencia significativa que permite oponerlos antonímicamente ('del interior al exterior' / 'del exterior al interior'), pese a la existencia de una base sémica común ('desplazamiento respecto a un recinto'). Ambos verbos se combinan con ablativo y adlativo (aunque en el discurso suelen omitirse algunas de estas valencias), si bien la focalización es inversa (salir de la reunión / entrar en Marruecos). 
(2006): «Semántica de formas materiales y semántica de formas de contenido», en Juan de Dios Luque Durán, ed., Homenaje al profesor José Andrés de Molina Redondo, vol. II, Granada, Granada Lingvistica, pp. 829-844.

, Inmaculada PENADÉS MARTínEZ, coords., y M. ${ }^{\mathrm{a}}$ Tadea DíAz Hormigo, ed. (1998): Estudios sobre el «Diccionario de uso del español» de María Moliner, Cádiz, Universidad de Cádiz.

COSERIU, Eugenio (1981): Principios de semántica estructural, Madrid, Gredos,

GARRIGA ESCRIBANO, Cecilio (2003): «La microestructura del diccionario: Las informaciones lexicográficas», en Antonia M. Medina Guerra, ed., Lexicografía española, Barcelona, Ariel, pp. 103-126.

GECKELER, Horst (1989): «Considérations sur les relations entre la synonymie et l'antonymie», en Actes du XVIII Congrès International de Linguistique et Philologie Romanes (Trier, 1986), Tübingen, Max Niemeyer, IV, pp. 254-263.

Gove, Philip B., ed. (1968): Webster's New Dictionary of Synonyms: A Dictionary of Discriminated Synonyms with Antonyms and Analagous and Contrasted Words, Massachusetts, G. $\alpha$ C. Merrian, Springfield.

GUTIÉRREZ ORDÓÑEZ, Salvador (1981): Lingüistica y semántica. (Aproximación funcional), Oviedo, Universidad de Oviedo.

HAENSCH, Günther (1997): Los diccionarios del español en el umbral del siglo XXI, Salamanca, Universidad de Salamanca.

et al. (1982): La Lexicografía. De la lingüística teórica a la lexicografía práctica, Madrid, Gredos.

JimÉNEZ Ríos, Enrique (2001): Variación léxica y diccionario. Los arcaísmos en el diccionario de la Academia, Madrid, Iberoamerica Vervuert.

LYONS, John (1971): Introducción en la lingüística teórica, Barcelona, Teide. (1980): Semántica, Barcelona, Teide.

Moliner, María (1966-1967): Diccionario de uso del español, Madrid, Gredos.

Moreno FernánDEZ, Francisco (2000): Qué español enseñar, Cuadernos de didáctica español /LE, Madrid, Arco/Libros.

MuÑoz NúÑEZ, M. ${ }^{a}$ Dolores (1999): La polisemia léxica, Cádiz, Universidad de Cádiz.

PENADÉS MARTíNEZ, Inmaculada (1994): «La clasificación semántica del adjetivo calificativo en español (Revisión crítica)», en Actes du XVIIIe Congrès International de Linguistique et de Philologie Romanes (Trier, 1986), Tübingen, Max Niemeyer, II, pp. 196-207.

RODRÍGUEZ ADRADOS, Francisco (1967): «Estructura del vocabulario y estructura de la lengua», en Problemas y principios del estructuralismo lingüistico, Madrid, CSIC, pp. 193-229.

SALVADOR, Gregorio (1981): Semántica y lexicología del español. Estudios y lecciones, Madrid, Paraninfo.

VARO VARO, CARMEN (2006): “Algunas observaciones sobre la aplicación del concepto de “oposición” en Lexicología”, en Juan de Dios Luque Durán, ed., Homenaje al profesor José Andrés de Molina Redondo, Granada,Granada Lingvistica, II, pp. 819-827. (2007): La antonimia léxica, Madrid, Arco/Libros.

ZAINQUI, José María (1991): Diccionario razonado de sinónimos y contrarios, Barcelona, Editorial De Vecchi. 